\title{
Current state of screening high-ACE youth and emerging adults in primary care
}

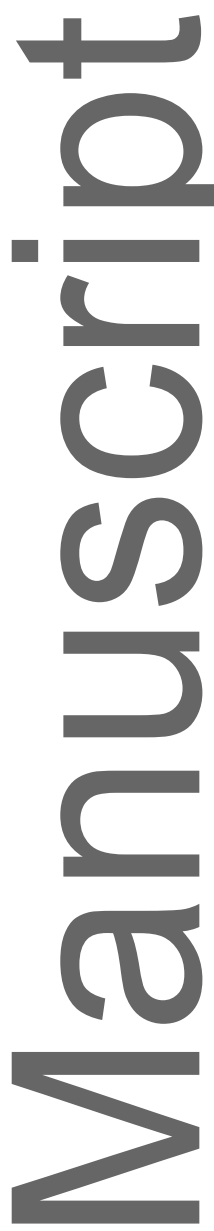

\author{
Michelle Pardee DNP, FNP-BC* \\ Clinical Assistant Professor
}

The University of Michigan School of Nursing

426 N. Ingalls, \#4130

Ann Arbor, MI 48109

milopa@umich.edu

milopa@med.umich.edu

734-647-0132

*corresponding author

Elizabeth Kuzma DNP, FNP-BC

Clinical Assistant Professor

The university of Michigan School of Nursing ekuzma@umich.edu

Chin Hwa (Gina) Y. Dahlem, PhD, FNP-C, FAANP

Clinical Assistant Professor

The University of Michigan School of Nursing ginayi@umich.edu

Nicole Boucher PhD, CPNP

Clinical Assistant Professor

The University of Michigan School of Nursing nbouche@.umich.edu

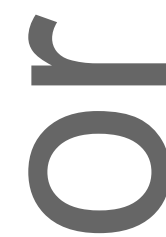

Cynthia S. Darling-Fisher PhD, FNP-BC

Clinical Associate Professor

The University of Michigan School of Nursing

darfish@umich.edu

Michelle Pardee: as lead author developed the idea for the article, co-wrote the risk assessment tool, discussion and clinical implication sections, as well as editing and final manuscript preparation for submission.

Elizabeth Kuzma: co-wrote the introduction and background section as well as extensive editing of the overall article and table

This is the author manuscript accepted for publication and has undergone full peer review but has not been through the copyediting, typesetting, pagination and proofreading process, which may lead to differences between this version and the Version of Record. Please cite this article as doi: 10.1002/2327-6924.12531.

This article is protected by copyright. All rights reserved. 
Gina Dahlem: developed the table and co-wrote the risk assessment tool section in the body of the article, as well as overall editing of the manuscript.

Nicole Boucher: co-wrote the introduction and background section, as well as overall editing of the manuscript.

Cindy Darling-Fisher: co-wrote the discussion and clinical implication section of the paper, as well as overall editing of the manuscript.

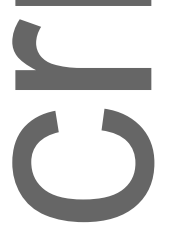

\section{Acknowledgements}

The authors would like to acknowledge the Complex Adverse Childhood Experience and Complex Aid (CAsCAid) faculty group at the University of Michigan School of Nursing for their support and encouragement in the writing of this manuscript. All (five) authors are members of CAsCAid, with funding for the work group provided by the University of Michigan School of Nursing's Dean's Centennial Seminar Series.

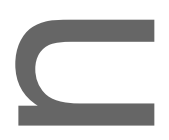

Background \& Purpose:

Abstract

Trauma comes in many forms, including interpersonal, community, and institutional trauma. The Adverse Childhood Events (ACE) studies demonstrated that adverse experiences in childhood can have a profound, cumulative impact on the course of health and development over a lifetime. It is critical for health care providers, such as nurse practitioners (NPs), working in primary care to screen adolescents and emerging adults for a history of ACEs and trauma. Areview of current assessment tools used in assessing this population in health settings is needed to determine how screening for ACEs is being done.

\section{Conclusions:}

Clinically efficient tools for screening and assessment of high-ACE youth in primary care settings are lacking. Developing a process to assess ACEs, risk behaviors, physical and mental health status that is efficient to use during a time limited clinical visit, is an important step in providing holistic care to a challenging population.

\section{Implications for Practice:}

Primary care NPs are in the perfect position to implement assessments of ACEs through trauma-informed nursing care. ACE assessment in clinical practice will provide vital information to guide the development of tailored interventions for reducing risk behaviors and mitigate the long term impacts of ACEs.

\section{Introduction}


Trauma comes in many forms, including interpersonal, community, and institutional trauma. Unfortunately, trauma is something nearly everyone has been exposed to in some capacity, whether it is from personal experiences, those of families, friends, or neighbors (Van der Kolk, 2014; Wade, Shea, Rubin, \& Wood, 2014). Data from the Centers for Disease Control and Prevention [CDC] (2016a) shows that severe trauma has been experienced by many children, including physical or sexual abuse and neglect. These severe traumatic experiences are also termed an adverse childhood event (ACE). See Table 1 for currently identified ACEs. Research has shown that ACEs leave long lasting marks on individuals' brains, mental health, biology, and physical health. Felitti et al's (1998) landmark study found that ACEs increased the risk of neurological, biological, and psychological/psychosocial difficulties. These included: changes in brain neurobiology; social/ emotional/cognitive impairment; use of maladaptive coping behaviors (smoking, substance abuse, self-harm, violence); and severe and persistent behavioral health, physical health and social problems, leading to early death (Felitti et al., 1998). The ACE studies have demonstrated that adverse experiences in childhood can have a profound, cumulative impact on the course of health and development over a lifetime (Felitti et al., 1998; Kalmakis \& Chandler, 2015; Strine et al., 2012).

Given the significant consequences of ACEs, it is critical for health care providers, such as nurse practitioners (NPs), working in primary care to screen patients for a history of ACEs and trauma (Kalmakis \& Chandler, 2015). The purpose of this article is to review the current screening approaches used to assess youth and emerging adults in primary care, describe their strengths and limitations in the assessment of ACE exposure for this population, and discuss the need for NPs to integrate screening for ACEs in adolescents and emerging adults into their clinical practice as part of trauma-informed care.

\section{Background and Significance}


Adverse childhood experience (ACE) is used to describe traumatic events, such as abuse and neglect, that an individual may experience under the age of 18 (CDC, 2016c). Since the first study about ACEs was published, the types of adverse childhood experiences has broadened to include exposure to a wide range of potentially traumatic events including, but not limited to, personal victimization, challenging family circumstances and stressors, r community stressors, as well as economic hardship and housing instability (Wade, Shea, Rubin, \& Wood, 2014).

ACEs are much more common than one would expect. One in five children have been sexually molested, one in four have been abused by a parent to the point of leaving a physical mark, one in four have alcoholic relatives, and one in eight have witnessed physical violence in their home (CDC, 2016a). The Behavioral Risk Factor Surveillance System (BRFSS), which has collected ACE data from non-institutionalized adults in the United States (US) since 2009 in 32 states including the District of Columbia and three U.S. territories, found that approximately two-thirds of surveyed adults reported at least one ACE, and more than one in five reported three or more ACEs (CDC, 2016b). Using the most current data from the 2011-2012 National Survey of Children's Health (NSCH), approximately half of US children have experienced at least one ACE while older children, those with lower household income, and those in foster care are more likely to have had one or more ACEs (Bethell et al., 2014; Burns et al, 2004). The negative impact of ACEs on youth can be profound and affect their lifelong health, well-being, and quality of life.

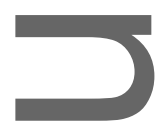

\section{Brain Development and Trauma}

The human brain is designed to respond to stressful stimuli for survival. In acutely stressful situations the brain's stress response tells the body to produce stress hormones; these lead to the physiologic responses known as "fight or flight" and "freeze or faint," with the 
latter occurring when no escape is feasible (Van der Kolk, 2014). More research has focused on the physiology of the "fight or flight" response, such that its adverse effects are better known. In the fight or flight response, the stress hormone cortisol is released, thus beginning a series of physical responses that prepare the body to respond to the stressful stimuli. In a resilient individual, without a history of trauma, once the acute stressor is eliminated, the body returns to its normal state. For those with a history of trauma, such as physical abuse, the brain's response to stress is much different due to the changes in the brain structure and function as a result of past traumatic events or experiences (Van der Kolk, 2014).

Research shows that trauma and ACEs impair neurodevelopment and can lead to multiple significant and longstanding changes in the brain structure and function (De Bellis \& Zisk, 2014). When a significant traumatic event takes place or a series of traumatic events occur, the impact can be long lasting. While the rational brain may seek to move past the trauma, the survival part of the brain of someone with a history of trauma, can remain activated in "fight or flight;" prepared to respond to even the smallest sign of stress or perceived danger. The brain then resets its alarm system, making it hypersensitive; perceiving normal daily activities and encounters as threats. This then signals the body to release large amounts of stress hormones for protection. Consequently, the body's normal adaptation to stress becomes maladaptive and dysfunctional following trauma. This in turn can lead to impulsivity and aggressive behavior since the brain remains in a hyper-reactive state (Van der Kolk, 2014).

A trauma experience impairs the communication between the right and left side of the brain either temporarily during the traumatic event or periodically following trauma (Van der Kolk, 2014).The right side of the brain is the more intuitive, emotional, creative side that stores memories as sensations such as touch, sound, and smell. Emotions can be evoked when similar sensations are experienced at different times. The left side is the analytic, logical, 
rational side of the brain that connects vocabulary and facts to experiences. The left side of the brain allows one to verbalize and describe memories to explain experiences. This disconnect between the sides of the brain impairs one's ability to put feelings into words and sequence events rationally and logically: to identify cause and effect, assess consequences of actions, and set long-term goals for the future. This disconnect, impacts behavior which can lead to aggressive or violent behavior, substance use, delinquency, learning disabilities, and developmental problems in adolescents (Balistreri \& Alvira-Hammond, 2016; Bethell et al., 2014; Fox et al., 2015; Thompson et al., 2015).

\section{Mental Health and Trauma}

Trauma also has a profound negative impact on mental health. Nearly eighty percent of young adults with a history of abuse have experienced problems with anxiety, depression, suicide attempts, and eating disorders. Additionally, ACEs can predispose survivors to developing long-term problems such as conduct disorders, posttraumatic stress disorder (PTSD), attention deficit disorder, and learning disabilities. The most current data, from the 2011-2012 NSCH found that children with two or more ACEs were at increased risk for depression, anxiety, and PTSD (Balistreri \& Alvira-Hammond, 2016; Fox et al., 2015; Thompson et al., 2015).

\section{Physical Health and Trauma}

The effects of trauma on the brain, mental health, and the chronic stress response have been associated with negative physical health outcomes. ACEs have been shown to be a significant contributor to the leading causes of death. In the Felitti et al., (1998) landmark ACE study of 17,000 adults over a 10-year period; four or more ACEs were associated with four- to 12 -fold greater risk for alcoholism, drug abuse, depression, and suicide attempts. The 
study also found a two- to four-fold increase in smoking, poor self-rated health, and sexually transmitted disease; and a 1.4- to 1.6-fold increase in physical inactivity and severe obesity. The number of ACEs a person experienced were associated with a graded relationship to chronic diseases including ischemic heart disease, cancer, chronic lung disease, skeletal fractures, and liver disease. Given their impact on individual and population health, screening for and addressing ACEs in clinical practice can provide a critical opportunity to improve public health in terms of both individual and population outcomes (Petersen et al., 2014).

In order to better understand whether or not ACEs are evaluated in the primary care of adolescents and emerging adults, it is important to review the current assessment tools available. Research has shown that adolescents respond positively to the use of assessment tools in the primary care setting to introduce and address sensitive topics (Martyn et al., 2012). Consequently, there are several screening methods used in adolescent health settings. Several of these methods will be the focus of this paper. The included tools range from standard history assessment tools used to identify risk behaviors to ACE assessment tools used in research.

\section{Risk Assessment Tools for Adolescents and Emerging Adults}

Six screening tools will be discussed; two used in research and four utilized in clinical practice (see Table 2). The original ACE survey and the ACE survey (revised) are used exclusively in research; while, Guidelines for Adolescent Preventive Services (GAPS), Rapid Assessment for Adolescent Preventive Services (RAAPS), Bright Futures, and the HEEADSSS assessment mnemonic [్ome environment, Education and employment, Eating,

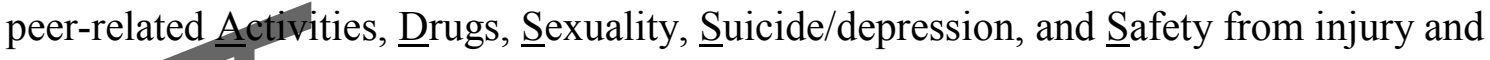
violence], are predominantly utilized in clinical practice. The clinical assessment tools were chosen, as they are standard of care for assessment of adolescents and emerging adults in primary care. Four methods (GAPS, RAAPS, Bright Futures, HEEADSSS) predominantly 
assess for risk behaviors and do not address adverse childhood experiences. In contrast, the ACE survey has been used for research with adults, rather than in a clinical setting, but a revision has recently been created for research with youth (Finkelhor et al., 2015).

The value and significance of using psychosocial and risk assessments tools with adolescents has been well established (Klein, Goldenring, \& Adelman, 2014). However, the available assessments tend to focus primarily on the risk behaviors youth engage in and less on specific life experiences (e.g. ACEs) that may play a role in the development of those risk behaviors and associated adverse health consequences. Key aspects of each approach are described below and Table 2 provides a comparison of the screening tools, highlighting their strengths and limitations.

\section{Research Focused ACE Assessment Tools}

The original ACE assessment. The ACE and revised ACE surveys have received considerable attention since they have demonstrated that adverse childhood experiences are strongly relatedto adult health risks and higher mortality rates. Despite their importance, there is little information about the application of the ACE surveys as risk assessment tools in a busy primary care clinical practice for any age group (Felitti et al., 1998; Finkelhor et al., 2015; Finkelhor et al., 2013). While the original ACE survey is brief, it was developed for use in research with 55-57-year-old obese adults recalling childhood (Felitti et al., 1998). This potentially causes errors or deletions regarding events of the past as it relies on an individual's memory.

The revised ACE survey. This tool was developed for research use with adolescents; though was discussed for use as an assessment tool in clinical practice (Finkelhor et al., 2013). It includes some of the original ACE questions, excludes others and adds contemporary issues that adolescents and emerging adults face that have shown to be harmful to growth and development and mental health (Finkelhor et al., 2013). The 
additional events include: peer victimization (bullying), adversities faced by low income urban youth (witness violence), youth in foster care, those with housing instability, and minority youth, including those who identify as lesbian, gay, bisexual, or transgender (LGBT) (Blosnich \& Anderson, 2015; Riebschleger, Day, \& Damashek, 2015; Wade, Shea, Rubin, \& Wood, 2014).

\section{Clinically Focused Risk Assessment Tools for Adolescents and Emerging Adults} The Guidelines for Adolescent Preventative Services (GAPS). The GAPS assessment was ground-breaking when it was developed and introduced by the American Medical Association (AMA), as an adolescent specific risk assessment tool in 1993 to be used in clinical settings (Elster \& Kuznets, 1994). GAPS is no longer supported by the American Medical Association and has not been updated to include contemporary issues and concerns. Many providers now utilize measures that have evolved based on GAPS, such as the RAAPS assessment. Both of these tools, focus on current risk behaviors that impact physical and mental health, and can lead to long-term physical and mental health problems. Some include attention to abuse history (as detailed table 1), but neither includes all of the ACE related questions.

RAAPS. RAAPS was developed from GAPS to provide a more efficient screening tool to use in a busy clinic setting (Yi, et al, 2009). RAAPS is a standardized and validated, 21 item risk assessment survey designed for 9-24 year olds to be used in office settings (Possibilities for change, 2017). The RAAPS tool screens for the top risk behaviors that contribute most to the morbidity and mortality of adolescents (Yi, et al., 2009) and comes in a paper or web-based format (Possibilities for change, 2017). The two RAAPS formats allow for youth to complete the surveys confidentially which is optimal when obtaining sensitive information from adolescents. RAAPS is used in many school-based and school-linked adolescent health centers around the United States (Possibilities for change, 2017). 
Bright Futures. The Bright Futures tool (https://brightfutures.aap.org/materials-andtools/tool-and-resource-kit/Pages/adolescence-tools.aspx) is frequently used as the standard of care in pediatric practices; however, it is not commonly used in adolescent specific health centers. The Bright Futures assessment questions are general, focus on risk behaviors, and do not provide the specific information needed to assess and mitigate the impact of ACEs (AmericanAssociation of Pediatrics [AAP], 2017). The accuracy of the information obtained may be in question, as it is typically completed by the parent, rather than the patient. Parents may or maynot know of the risk behaviors engaged in by their adolescent. Furthermore, the adolescent may not disclose maltreatment, violence or other household dysfunction queried by the tool, with the parent in close proximity.

HEEADSSS. The HEEADSSS mnemonic is another commonly used method for assessment of adolescent and emerging adult risks often used in adolescent medicine to assess the home environment, education and employment, eating, peer-related activities, $\underline{\text { drug }}$ use, sexuality, suicidal ideation/depression, and safety from injury and violence. This mnemonic is now included in Bright Futures adolescent assessment tools (ages 11-21) (AAP, 2017) and provides guidance for areas the provider should cover during the clinic visit.

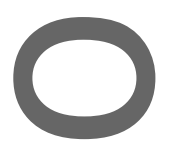

\section{Discussion}

Early identification of ACEs, can facilitate referrals and interventions to help mitigate the potential lifelong adverse health consequences of adverse childhood experiences. Routine screening for ACEs in primary care has been encouraged; though studies have focused on screening of adult patients (Glowa, Olson \& Johnson, 2016; Kalmakis \& Chandler, 2015; Kalmakis etal., 2017). Glowa, Olson \& Johnson (2016), found that it is feasible to screen adults for ACEs in a busy primary care family medicine setting; while time constraints have been identified by primary care NPs (Kalmakis et al., 2017). Kalmakis et al. (2017), found that NPs lack confidence in screening adults for histories of child abuse and indicated that 
education regarding screening would be beneficial. The NPs also indicated that including an assessment within the electronic medical record would help prompt this challenging discussion (Kalmakis, et al., 2017). These findings can easily be translated into primary care with the adoleseent and emerging adult population and indicates a need for NPs to obtain education regarding ACEs, how to screen for ACEs and how to intervene if indicated. It also indicates a meed for an efficient assessment tool that can be used in a busy primary care setting.

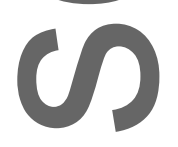

\section{Clinical Implications}

Given the documented impact of ACEs on individuals' long-term development and health, it's important for providers to screen and assess for prior and current or ongoing ACE exposure as they develop interventions to reduce risk and promote health. This is particularly important in the adolescent and emerging adult populations given the ongoing development of the adolescent brain, in particular, related to decision-making and executive functioning. Adolescents are developing health habits and life plans, ideally with the support of, but also separate from their parents, sometimes leading to risk behaviors in their pursuit of independence. However, this is also a time when interventions can help promote resilience and positive health behaviors.

For adolescents and emerging adults, it is critical for NPs to assess and provide secondary and tertiary interventions to reduce severity and consequences of ACEs (Oral, et al., 2016).Trauma informed interventions in the early childhood years tend to focus on strengthening parent-child relationships to promote positive child development even in the presence of adverse life events. With adolescents, it is common for providers to obtain general health information from parents, while also obtaining confidential information from the adolescent, during health care visits. This practice promotes adolescents' ownership and independence in their healthcare and obtains confidential information about participation in 
risk behaviors. Adding routine assessment of ACEs could be feasible in this confidential part of the visit as well. Understanding the adverse events adolescents and emerging adults have been exposed to and are currently coping with can provide important information needed to best tailor interventions to meet individual's needs and reduce the physical and mental health consequences of ACEs.

\section{NPs Role in Providing Trauma-Informed Care}

There is a call to create a "culture of health" which integrates trauma-sensitive screening, assessment and interventions in both mental health and physical health care as well as connection to and development of community resources (Dentzer, 2015). The Substance Abuse and Mental Health Services Administration (SAMHSA)(2014) endorses a trauma informed care model for providers to recognize the prevalence of trauma and its pervasive impact on the lives of patients and the need to develop trauma-sensitive or trauma-responsive services. Trauma informed-care is a shift in how organizations and providers comprehensively view and approach trauma (Oral et al., 2016).

Nurses are at the forefront of these changes given their holistic perspectives on care for individuals and families in the community (Dentzer, 2015) and across all settings. Nurses and NPs, in particular, are in a position to develop and implement appropriate traumainformed strategies for high-risk youth. To move this initiative forward, it is essential to develop efficient methods of screening for and identification of ACEs in general primary care settings.

The first step is for providers to recognize the impact of trauma and ACEs on health and development in order to integrate trauma-informed practices in their assessments and interventions. SAMHSA (2014) identifies concepts of trauma informed clinical practices such as building a trauma informed work force that is trauma aware and knowledgeable about the impact and consequences associated with trauma experiences. This includes utilizing 
appropriate trauma related screening and assessment tools so that referrals and interventions can be strength-based and acknowledge resilience of survivors (SAMHSA, 2014). While there are increasing numbers of clinics nationwide developing services and guidelines for working with children and families experiencing trauma, there are few tools that help the primary care provider efficiently assess those at risk in order to be able to focus limited resources on those in the greatest need.

\section{Need for Standardized Screening Tools for ACEs}

Clinically efficient tools for screening and assessment of youth in primary care settings are lacking. Current tools either focus specifically on ACEs, current risk behaviors, or give a broad perspective on the current life situation. While these perspectives are useful, it would be ideal to have an instrument that looks at risk behaviors in the context of the adolescent's life experiences. Developing a process to assess ACEs, risk behaviors, physical and mental health status that is efficient to use during a time limited clinical visit, is an important step in providing holistic care to a challenging population.

One option is to utilize the event history calendar (EHC) approach described by Martyn et al. (2012), to facilitate the contextual assessment of prior and ongoing ACEs to identify strengths and risk behaviors to tailor interventions to promote health. The EHC is a structured, yet flexible assessment tool that facilitates recall of past events by utilizing past experiences as cues to remembering (Martyn et al., 2013). This calendar approach (see Figure 1) can be adapted to any population and specialty, to obtain pertinent information; which in this case is history of, or ongoing ACEs (such as physical, mental, sexual abuse; neglect; violence), in addition to risk behaviors and individual strengths. It allows adolescents to consider how life experiences like an ACE, family separation, divorce, or death may have impacted the start of risk behaviors. The EHC could be done annually, to determine if there are any changes in the adolescent or emerging adult's life and to provide guidance for 
interventions to reduce the impact of ACEs and to promote long-term health outcomes. This approach has been well received by both, adolescents and providers and found to not add significantly to clinic visit time (Martyn et al., 2012).

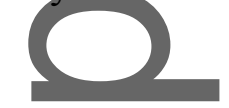

-

\section{Conclusion}

Primary care NPs are in the perfect position to implement assessment of ACEs in adolescents and emerging adults through trauma-informed nursing care. The significance of early childhood trauma on individual and population health and well-being is well established in the literature and now needs to be translated into practice. In order to effectively and efficiently assess for ACEs in the clinical setting a clinical history tool must be developed to be used alongside a risk assessment tool to better understand those risk behaviors. Nurse practitioners can play a pivotal role in the development and implementation of these clinically efficient ACE assessment tools. Introducing ACE assessment in clinical practice will provide vital information to guide the development of tailored interventions for reducing risk behaviors and mitigate the long term impacts of ACEs.

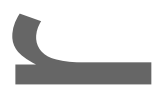

\section{References}

American Association for Nurse Practitioners (AANP). (2015). Quality of nurse practitioner practice. Retrieved from

https://www.aanp.org/images/documents/publications/qualityofpractice.pdf. American Academy of Pediatrics (AAP), (2017). Bright Futures. $4^{\text {th }}$ edition. Retrieved from: https://brightfutures.aap.org/materials-and-tools/tool-and-resourcekit/Pages/adolescence- tools.aspx.

Balistreri, K.S., \& Alvira-Hammond, M., (2016). Adverse childhood experiences, family functioning and adolescent health and emotional well-being. Public Health. 132, 72 78. 
Bethell, C.D., Newacheck, P., Hawes, E., \& Halfon, N., 2014. Adverse Childhood

Experiences: Assessing The Impact On Health and School Engagement and The Mitigating Role of Resilience. Health Affairs. 33, 2106-2115.

Blosnich, I. R, Andersen, J. P. (2015). Thursday's child: The role of adverse childhood experiences in explaining mental health disparities among lesbian, gay, and bisexual

US adults. Social Psychiatry Psychiatric Epidemiology, 2015(50), 335-338. doi: 10.1007/s00127-014-0955-4.

Burns, B.J.,Phillips, S.D., Wagner, H.R., Barth, R.P., Kolko, D.J., Campbell, Y., et al., (2004). Mental health need and access to mental health services by youths involved with child welfare: A national survey. Journal American Academy Child Adolescent Psychiatry. 43, 960-970.

Center for Disease Control and Prevention [CDC]. (2016a). Child Abuse and Neglect:

Consequences. Retrieved from

https://Www.cdc.gov/violenceprevention/childmaltreatment/consequences.html.

Center for Disease Control and Prevention [CDC]. (2016b). BRFSS ACE data. Retrieved from:

https://www.cdc.gov/violenceprevention/acestudy/ace_brfss.html.

Center for Disease Control and Prevention [CDC]. (2016c). ACE survey. Retrieved from:

https://www.cdc.gov/violenceprevention/acestudy/.

De Bellis, M. D., \& Zisk, A. (2014). The biological effects of childhood trauma. Child and Adolescent Psychiatric Clinics of North America, 23(2), 185-222.

doi.org/10.1016/j.chc.2014.01.002

Dentzer, S. (2015). Why Nursing is a Key to Cultural Health. Robert Wood Johnson Culture of Health Blog. http://www.rwjf.org/en/culture-of health/2015/10/why_nursing_is_keyt.html. 
Elster, A.B. \& Kuznets, N.J., (Eds). (1994). American Medical Association guidelines for adolescent preventive services (GAPS): recommendations and rationale. Baltimore: Williams \& Wilkins.

Felitti, V.J., Anda, R.F., Nordenberg, D., Williamson, D.F., Spitz, A.M., Edwards, V., et al., (1998). Relationship of childhood abuse and household dysfunction to many of the leading causes of death in adults - The adverse childhood experiences (ACE) study. American Journal Preventive Medicine. 14, 245-258.

Finkelhor, D.,Shattuck, A., Turner, H., Hamby, S. (2013). Improving the Adverse Childhood

Experiences Study Scale. JAMA Pediatrics 167(1):70-75. Published online November 26, 2012. doi:10.1001/jamapediatrics.2013.420.

Finkelhor,D., Shattuck, A., Turner, H., Hamby, S. (2015). A revised inventory of Adverse Childhood Experiences. Child Abuse \& Neglect, 48, 13-21. doi:10.1016/j.chiabu.2015.07.011.

Fox, B.H., Perez,N., Cass, E., Baglivio, M.T., \& Epps, N., (2015). Trauma changes everything: Examining the relationship between adverse childhood experiences and serious, violent and chronic juvenile offenders. Child Abuse \& Neglect. 46, 163-173. Gallup. (2015). Americans rate nurses highest on honesty, ethical standards. Retrieved from http://www.gallup.com/poll/180260/americans-rate-nurses-highest-honesty-ethicalstandards.aspx.

Glowa, P., Olson, A., Johnson, D. (2016). Screening for adverse childhood experiences in a family medicine setting: A feasibility study. Journal of the American Board of Family Medicine, 29, 303-307. doi: 10.3122/jabfm.2016.03.150310. Kalmakis, K.\& Chandler, G. (2015). Health consequences of adverse childhood experiences: A systematic review. Journal of the American Association of Nurse Practitioners, 27, 457- 465. doi: 10.1002/2327-6924.12215. 
Kalmakis, K., Chandler, G., Roberts, S. \& Leung, K. Nurse practitioner screening for childhood adversity among adult primary care patients: A mixed-method study. Journal

of the American Association of Nurse Practitioners, 29, 35-45. doi: 10.1002/23276924.1237

Klein, D. A., Goldenring, J. M., \& Adelman, W. P. (2014). Probing for scars: How to ask the essential questions. Contemporary Pediatrics, 31(1), 16-28.

Martyn, K.K., Darling-Fisher, C., Pardee, M., Ronis, D.L., Felicetti, I.L., \& Saftner, M.A. (2012). Improving Sexual Risk Communication with Adolescents Using Event History Calendars. Journal of School Nursing, 28(2), 108-115. doi: $10.1177 / 1059840511426577$.

Martyn, K.K., Munro, M., Darling-Fisher, C., Ronis, D......Fava, N. (2013). Patientcentered communication and health assessment with youth. Nursing Research, 62(6), 383-393

\section{DOI: $10.1097 / \mathrm{NNR} .0000000000000005$.}

Oral, R., Ramirez, M., Coohey, C., Nakada, S...... Peek-Asa, C. (2016). Adverse childhood experiences and trauma informed care: The future of health care. Pediatric

Research, $79(1), 227-233$. doi: 10.1038/pr2015.197.

Petersen, A.C., Joseph, J., \& Feit, M., (2014). New directions in child abuse and neglect research, National Academies Press.

Possibilities for Change. (2017) The rapid assessment for adolescent preventative services@ (RAAPS). Retrieved from: http://www.possibilitiesforchange.com/raaps/.

Riebschleger, J., Day, A. \& Damashek, A. (2015). Foster care youth share stories of trauma before, during, and after placement: Youth voices for building trauma-informed systems of care. Journal of Aggression, Maltreatment \& Trauma, 24(4),339-360, doi: 10.1080/10926771.2015.1009603. 
Substance Abuse and Mental Health Services Administration (SAMHSA), (2014). "Guiding Principles of Trauma Informed Care”. Treatment Improvement Protocols (TIP) 57:

https://www.samhsa.gov/samhsaNewsLetter/Volume_22_Number_2/trauma_tip/inde x.ht

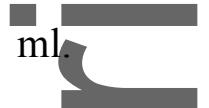

Strine, T.W., Dube, S.R., Edwards, V.J., Prehn, A.W., Rasmussen, S., Wagenfeld, M., et al., (2012). Associations Between Adverse Childhood Experiences, Psychological

Distress, and Adult Alcohol Problems. American Journal of Health Behavior. 36, 408423.

Thompson, R., Flaherty, E.G., English, D.J., Litrownik, A.J., Dubowitz, H., Kotch, J.B., et al., (2015). Trajectories of Adverse Childhood Experiences and Self-Reported Health at Age 18. Academic Pediatrics. 15, 503-509.

Van der Kolk, B. A. (2014). The body keeps the score: Brain, mind, and body in the health of trauma. New York: Penguin Books.

Wade, R., Shea, J. A., Rubin, A., \& Wood, J. (2014). Adverse childhood experiences of lowincome urban youth. Pediatrics 134(1), July 2014.

Yi, G., Martyn, K, Salerno, J., \& Darling-Fisher, C. (2009). Development and Clinical Use of Rapid Assessment for Adolescent Preventive Services (RAAPS) Questionnaire in School-based Health Centers. J Pediatr Health Care 23(1): 2-9. doi:10.1016/j.pedhc.2007.09.003.

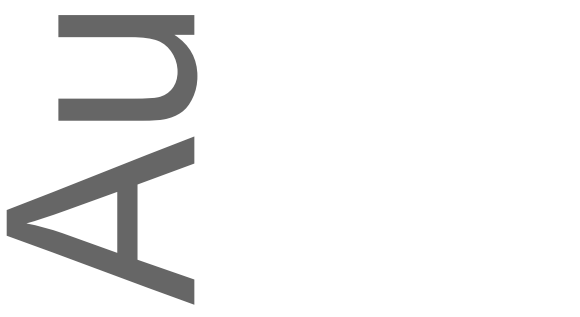




\begin{tabular}{|c|c|c|c|c|}
\hline Year & $\begin{array}{l}\text { Childhood } \\
\text { (as early as you can remember to } \\
\text { current) }\end{array}$ & $\begin{array}{c}2016 \\
\text { (Last Year) }\end{array}$ & $\begin{array}{c}2017 \\
\text { (Current Year) }\end{array}$ & $\begin{array}{c}2018 \\
\text { (Next Year) }\end{array}$ \\
\hline \multicolumn{5}{|l|}{ What is your Age? } \\
\hline \multicolumn{5}{|l|}{$\begin{array}{l}\text { What is your Grade in School } \\
\text { (grade, repeated grades, school } \\
\text { changes, \& if dropped out)? }\end{array}$} \\
\hline \multicolumn{5}{|l|}{ 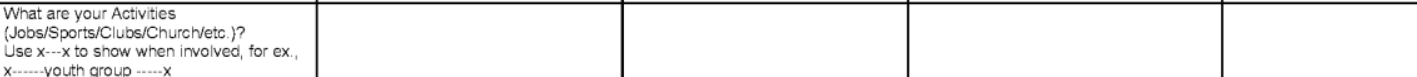 } \\
\hline \multicolumn{5}{|l|}{$\begin{array}{l}\text { Who are your Family and Friends? Other } \\
\text { important poople? (Circle who helps you) }\end{array}$} \\
\hline \multicolumn{5}{|l|}{$\begin{array}{l}\text { In your household have you withessed } \\
\text { one parent or other adult, hit, punch, } \\
\text { slap threaten the other parent or adult? }\end{array}$} \\
\hline \multicolumn{5}{|l|}{$\begin{array}{l}\text { In your neighborhood, have you } \\
\text { witnessed or been involved in violent } \\
\text { events - assault, robbery, accidents }\end{array}$} \\
\hline \multicolumn{5}{|l|}{$\begin{array}{l}\text { What happy/good memories or events } \\
\text { have you experienced? }\end{array}$} \\
\hline \multicolumn{5}{|l|}{$\begin{array}{l}\text { Have you felt lonely, rejected or that } \\
\text { nobody likes you? }\end{array}$} \\
\hline \multicolumn{5}{|l|}{$\begin{array}{l}\text { Have you had any of these behaviors? } \\
\text { Smoking, Alcohol, Drugs, Cutting, Eating } \\
\text { Problems, Others? For ex., } \\
\text { x--Drink Alcohol/Smoke Weed } \rightarrow\end{array}$} \\
\hline \multicolumn{5}{|l|}{$\begin{array}{l}\text { Have other kids includiling } \\
\text { brothers/sisters hit you, threaten you, } \\
\text { pick on your or insult you? }\end{array}$} \\
\hline \multicolumn{5}{|l|}{$\begin{array}{l}\text { Has a parent or other adult in the } \\
\text { household insult you, humiliate you or } \\
\text { made you feel affaid? }\end{array}$} \\
\hline \multicolumn{5}{|l|}{$\begin{array}{l}\text { Has a parent or other adult in the } \\
\text { household ever punch, grab, slap or hit } \\
\text { you so hard you had marks or injuries? }\end{array}$} \\
\hline \multicolumn{5}{|l|}{$\begin{array}{l}\text { Has a parent or other person ever touch } \\
\text { or fondle you in a sexual way? Attempt, } \\
\text { coerce or force you to have oral, anal, } \\
\text { vaginal sex? }\end{array}$} \\
\hline
\end{tabular}

Table 1

Identified ACEs

\begin{tabular}{ll|}
\hline - & Emotional Abuse \\
- & Physical Abuse \\
- & Sexual Assault \\
- & Photional neglect \\
- & Mother treated violently \\
- & Household substance abuse \\
- & Parental separation or divorce \\
- & Incarcerated household member \\
- & Low socioeconomic status* \\
- & Peer victimization* \\
- & Peer isolation/rejection* \\
- & Exposure to community violence* \\
& \\
*additional items in the revised ACE inventory \\
Finkelhor et al., 2015
\end{tabular}

Table 2 


\begin{tabular}{|c|c|c|c|}
\hline & Description & Benefits & Limitations \\
\hline $\begin{array}{l}\text { ACE } \\
\text { surv } \\
\text { ey }^{1}\end{array}$ & $\begin{array}{l}10 \text { item self-report survey to identify } \\
\text { childhood abuse (emotional, physical, and } \\
\text { sexual), neglect (emotional and physical), } \\
\text { and household dysfunction (related to } \\
\text { substance abuse, mental illness, domestic } \\
\text { violence, incarceration, and } \\
\text { divorce/separation) } \\
\text { This } 10 \text { item survey can be found and } \\
\text { downloaded free of charge from: } \\
\text { http://www.acesconnection.com/g/resource- } \\
\text { center/blog/resource-list-extended-aces- } \\
\text { surveys. Choose CDC-Kaiser Permanente } \\
\text { Ace Study link. } \\
\text { The original study questionnaires can be } \\
\text { fnilnd. }\end{array}$ & $\begin{array}{ll}\text { - } & \text { Brief } \\
\text { - } & \text { Yes/No } \\
\text { respons } \\
\text { es } \\
\text { - } & \text { Strong } \\
\text { research } \\
\text { to show } \\
\text { higher } \\
\text { ACE } \\
\text { scores, } \\
\text { the } \\
\text { greater } \\
\text { likelihoo } \\
\text { d of } \\
\text { physical } \\
\text { and } \\
\text { mental } \\
\text { health } \\
\text { problem } \\
\text { s as } \\
\text { adults }\end{array}$ & $\begin{array}{l}\text { - } \text { Retrospective } \\
\text { - } \text { Used as } \\
\text { research tool } \\
\text { Designed for } \\
\text { adults } 18 \text { and } \\
\text { older } \\
\text { - Possible } \\
\text { recall bias } \\
\text { - Does not } \\
\text { assess } \\
\text { additional } \\
\text { adversities } \\
\text { One feasibility } \\
\text { study in adults } \\
\text { for screening } \\
\text { in primary } \\
\text { care } \\
\text { No feasibility } \\
\text { studies in } \\
\text { youth for } \\
\text { screening in } \\
\text { primary care }\end{array}$ \\
\hline $\begin{array}{l}\text { Revi } \\
\text { sed } \\
\text { ACE } \\
\text { surv } \\
\text { ey }^{2}\end{array}$ & $\begin{array}{l}14 \text { item self-report survey that includes } \\
\text { additional adversities to the original ACE } \\
\text { survey } \\
\text { The survey can be viewed in this article } \\
\text { "Finkelhor, D., et al. (2015). A revised } \\
\text { inventory of adverse childhood } \\
\text { experiences. Child Abuse \& Neglect, 28, } \\
13-21, \text {, } \\
\text { https://doi.org/10.1016/j.chiabu.2015.07.01 }\end{array}$ & $\begin{array}{l}\text { - Includes } \\
4 \\
\text { additiona } \\
\text { I } \\
\text { adversiti } \\
\text { es } \\
\text { question } \\
\text { s: low } \\
\text { SES, } \\
\text { peer } \\
\text { victimiza } \\
\text { tion, } \\
\text { peer } \\
\text { isolation/ } \\
\text { rejection, } \\
\text { and } \\
\text { exposur } \\
\text { e to } \\
\text { communi } \\
\text { ty }\end{array}$ & $\begin{array}{ll}\text { - } & \text { Used as a } \\
\text { - } & \text { research tool } \\
\text { clinical } \\
\text { practice as a } \\
\text { screening tool } \\
\text { for youth } \\
\text { - } & \text { Retrospective } \\
\text { - } & \text { Possible } \\
& \text { recall bias }\end{array}$ \\
\hline
\end{tabular}

This article is protected by copyright. All rights reserved. 


\begin{tabular}{|c|c|c|c|c|}
\hline & & $\begin{array}{l}\text { violence } \\
\text { Researc } \\
\mathrm{h} \text { based } \\
\text { on youth } \\
\text { aged 10- } \\
17 \text { years }\end{array}$ & & \\
\hline $\begin{array}{l}\text { GAP } \\
\mathrm{S}^{3}\end{array}$ & $\begin{array}{l}54-58 \text { item survey used specifically for } \\
\text { adolescent screening tool developed for } \\
\text { youth aged } 11-21 \text { years old by American } \\
\text { Medical Association } \\
\text { AAPS is a product developed by the } \\
\text { longer available. }\end{array}$ & $\begin{array}{l}\text { - Adolesc } \\
\text { ent } \\
\text { specific } \\
\text { - } 2 \text { forms: } \\
\text { Younger } \\
\text { and } \\
\text { middle- } \\
\text { older } \\
\text { - Previous } \\
\text { ly gold } \\
\text { standard } \\
\text { of care } \\
\text { for } \\
\text { adolesce } \\
\text { nt health }\end{array}$ & \multicolumn{2}{|c|}{$\begin{array}{l}\text { Long } \\
\text { questionnaire: } \\
54-58 \\
\text { questions } \\
\text { Time } \\
\text { consuming to } \\
\text { complete } \\
\text { Last updated } \\
\text { in 1998; no } \\
\text { longer } \\
\text { supported }\end{array}$} \\
\hline $\begin{array}{l}\text { RAA } \\
\text { PS }^{4}\end{array}$ & $\begin{array}{l}\text { 21 item survey risk assessment survey } \\
\text { designed for } 9-24 \text { year olds to be used in } \\
\text { office settings } \\
\text { RAAPS is one of the adolescent } \\
\text { assessment products available for } \\
\text { purchase from Possibilities for Change; } \\
\text { http://www.possibilitiesforchange.com/raaps }\end{array}$ & $\begin{array}{ll}\text { - } & \text { Brief } \\
\text { - } & \text { Yes/No } \\
\text { Reponse } \\
\text { - } \\
\text { Web- } \\
\text { based or } \\
\text { Paper } \\
\text { - } 3 \\
\text { versions: } \\
\text { older } \\
\text { child (9- } \\
\text { 12), } \\
\text { adolesce } \\
\text { nt (13- } \\
18), \text { and } \\
\text { young } \\
\text { adult } \\
\text { (18-24) } \\
\text { Standar } \\
\text { d of care } \\
\text { at } \\
\text { School- } \\
\text { based } \\
\text { health } \\
\text { centers } \\
\text { Validate } \\
\text { d } \\
\text { Feasible } \\
\text { in }\end{array}$ & $\begin{array}{r}\text { Does } \\
\text { asses } \\
\text { ACE t } \\
\text { specif } \\
\text { quest } \\
\circ \\
\\
\\
\end{array}$ & $\begin{array}{l}\text { hot } \\
\text { for } \\
\text { auma } \\
\text { ons: } \\
\text { physic } \\
\text { al } \\
\text { neglec } \\
\text { t and } \\
\text { house } \\
\text { hold } \\
\text { dysfun } \\
\text { ction } \\
\text { due to } \\
\text { substa } \\
\text { nce } \\
\text { abuse } \\
\text { mental } \\
\text { illness } \\
\text { incarc } \\
\text { eration } \\
\text { divorc } \\
\text { e/sepa } \\
\text { ration } \\
\text { comm }\end{array}$ \\
\hline
\end{tabular}

This article is protected by copyright. All rights reserved. 


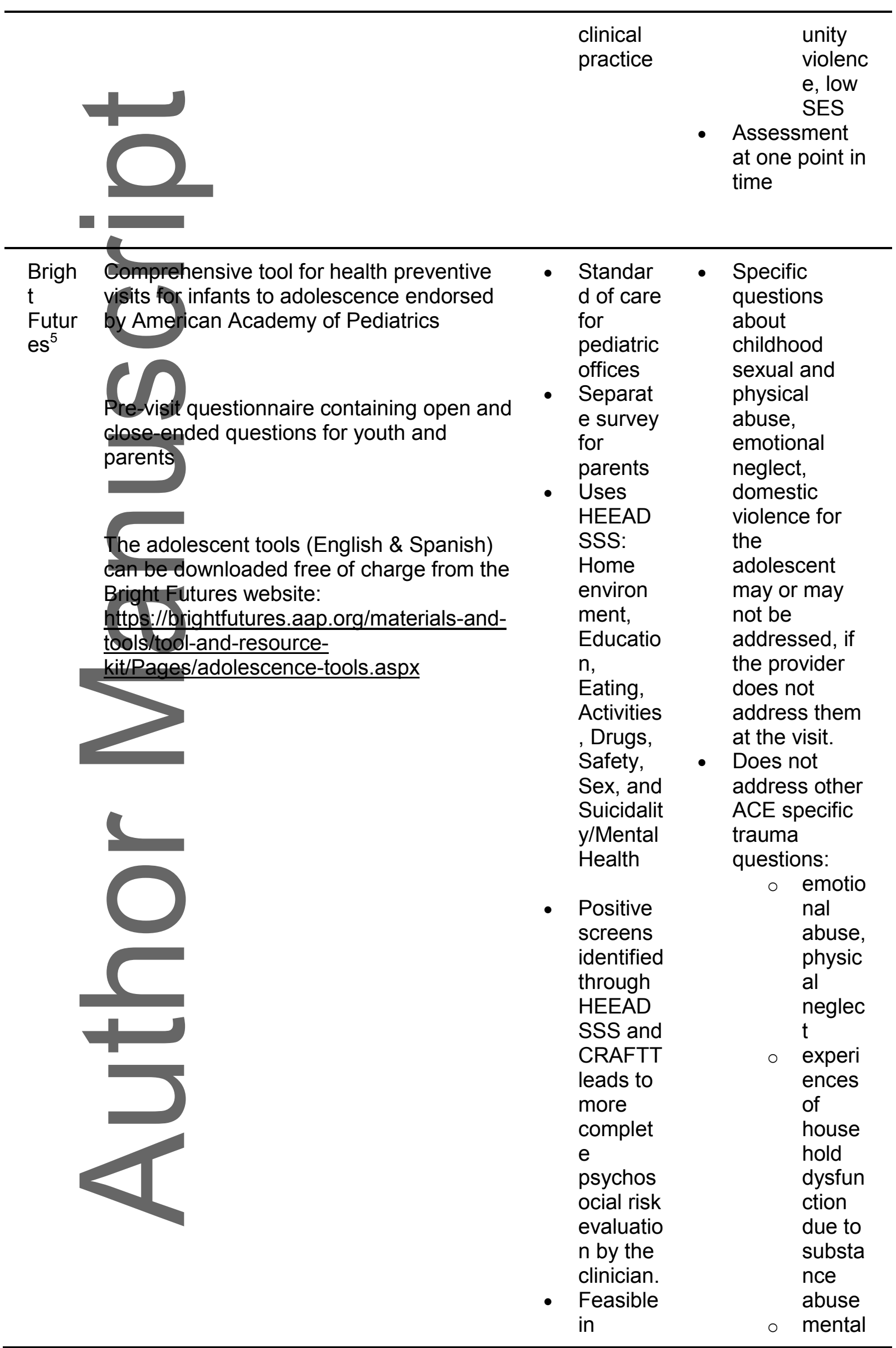

This article is protected by copyright. All rights reserved. 

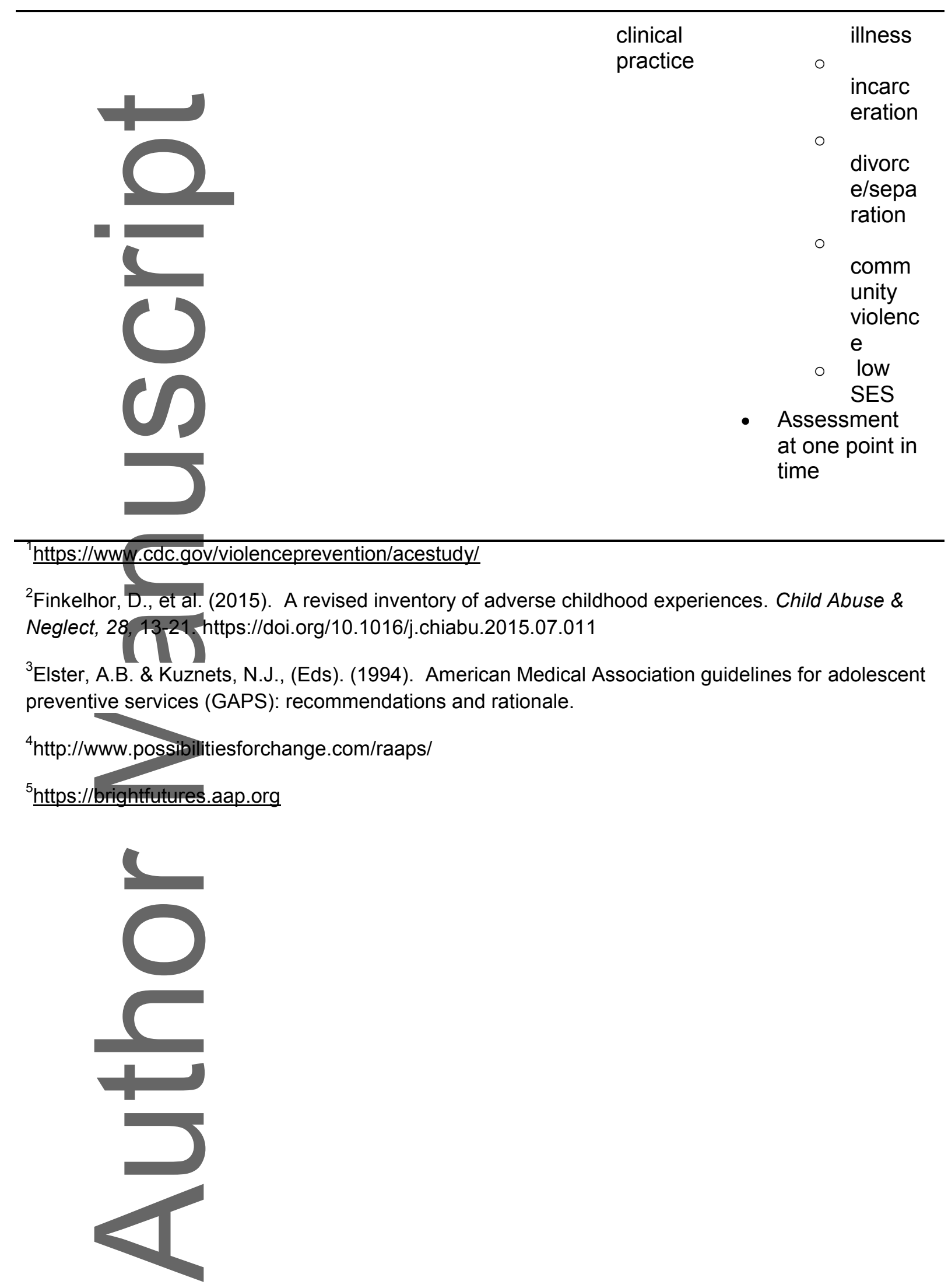

This article is protected by copyright. All rights reserved. 